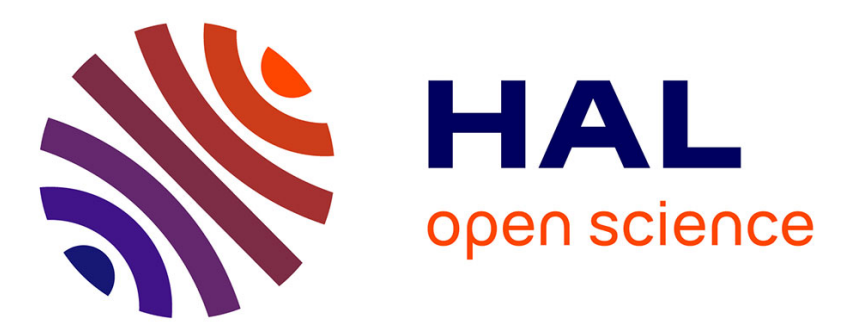

\title{
Mechanisms of hardening due to copper precipitates in $\alpha$-iron
}

David John Bacon, Yuri Osetsky

\section{To cite this version:}

David John Bacon, Yuri Osetsky. Mechanisms of hardening due to copper precipitates in $\alpha$-iron. Philosophical Magazine, 2009, 89 (34-36), pp.3333-3349. 10.1080/14786430903271377 . hal-00541682

\section{HAL Id: hal-00541682 \\ https://hal.science/hal-00541682}

Submitted on 1 Dec 2010

HAL is a multi-disciplinary open access archive for the deposit and dissemination of scientific research documents, whether they are published or not. The documents may come from teaching and research institutions in France or abroad, or from public or private research centers.
L'archive ouverte pluridisciplinaire HAL, est destinée au dépôt et à la diffusion de documents scientifiques de niveau recherche, publiés ou non, émanant des établissements d'enseignement et de recherche français ou étrangers, des laboratoires publics ou privés. 


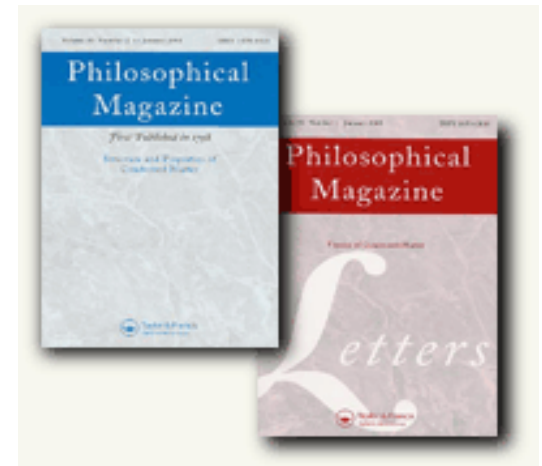

\section{Mechanisms of hardening due to copper precipitates in a- iron}

\begin{tabular}{|r|l|}
\hline Journal: & Philosophical Magazine \& Philosophical Magazine Letters \\
\hline Manuscript ID: & TPHM-09-Jun-0236.R1 \\
\hline Journal Selection: & Philosophical Magazine \\
\hline Date Submitted by the \\
Author: & $28-J u l-2009$ \\
\hline Complete List of Authors: & $\begin{array}{l}\text { Bacon, David; University of Liverpool, Engineering } \\
\text { Osetsky, Yuri; Oak Ridge National Laboratory }\end{array}$ \\
\hline Keywords: & atomistic simulation, dislocations, molecular dynamic simulations \\
\hline Keywords (user supplied): & Fe-Cu alloy, copper precipitates, alpha-iron \\
\hline &
\end{tabular}

\section{今) ScholarONE" \\ Manuscript Central}




\title{
Mechanisms of hardening due to copper precipitates in $\alpha$-iron
}

\author{
D.J. Bacon ${ }^{1 *}$ and Yu.N. Osetsky ${ }^{2}$ \\ 1) Department of Engineering, The University of Liverpool, Liverpool L69 3GH, UK \\ 2) Oak Ridge National Laboratory, P. O. Box 2008, Oak Ridge, TN 37831-6158 USA
}

\begin{abstract}
A comprehensive atomic-level simulation study has been made of interactions between a moving edge dislocation and copper precipitates that are initially coherent with the bodycentred-cubic matrix of alpha-iron Precipitates with diameter, $D$, in the range from 0.7 to $6 \mathrm{~nm}$ have been considered over the temperature range from 0 to $600 \mathrm{~K}$. For some combinations of temperature and $D$, the critical applied resolved shear stress, $\tau_{\mathrm{c}}$, at which the dislocation overcomes a row of precipitates with centre-to-centre spacing, $L$, is consistent with an elasticity treatment for strong obstacles, e.g. $\tau_{\mathrm{c}}$ is proportional to $L^{-1}$ and $\ln (D)$. This has a specific atomic-level origin, for the proportionality holds when the dislocation induces a partial transformation of the copper towards the more stable face-centred-cubic phase. The driving force for the transformation increases with decreasing temperature and increasing $D$, and so $\tau_{\mathrm{c}}$ has a strong temperature-dependence for large $D$. The results of these simulations, which employ a set of interatomic potentials of Finnis-Sinclair type, are seen to correspond well with experiments carried out elsewhere.
\end{abstract}

Keywords: Fe-Cu alloy; copper precipitates; alpha-iron; dislocations; molecular dynamics.

\footnotetext{
${ }^{*}$ Corresponding author:

e-mail $\quad$ djbacon@liv.ac.uk

tel. $\quad 01517944662$
} 


\section{Introduction}

In the 25 years since the seminal paper by Finnis and Sinclair (F-S) [1] that introduced the many-body interatomic potential formalism which bears their name, one of the most widely used potential set is that for the $\mathrm{Fe}-\mathrm{Cu}$ system in [2]. There are several reasons for this. First and foremost, there was, and still is, strong interest in the properties of atomic-scale defects in $\alpha$-iron and its alloys, driven by the need to understand and predict the behaviour of ferritic materials in existing and next-generation nuclear power systems. Exposure to fast neutrons from the fission reaction generates radiation damage in the form of point defects and their clusters, and the evolution of this damage with time can give rise to changes in dimensions and mechanical properties. The nature and magnitude of the changes depend on the properties of the vacancy and interstitial defects and their interaction with other microstructure features such as dislocations. These properties and interactions are determined by atomic-level features and so require simulation at that scale. In the multiscale framework of material modelling, the results of this simulation can be used in higher-level treatments based on either Monte Carlo or continuum approximations.

Copper $(\mathrm{Cu})$ in iron $(\mathrm{Fe})$ is important because $\mathrm{Cu}$-rich precipitates of small size (diameter $D<$ few $\mathrm{nm}$ ) form during neutron irradiation of ferritic pressure vessel steels that contain small amounts (a few tenths of a percent) of $\mathrm{Cu}$. $\mathrm{Cu}$ precipitates that nucleate during thermal ageing of $\mathrm{Fe}-\mathrm{Cu}$ alloys transform martensitically as they grow from the bodycentred cubic (BCC) crystal structure coherent with the Fe matrix to a twinned 9R form of the face-centred cubic (FCC) structure. The size at which they transform from BCC to $9 \mathrm{R}$ falls in the range from about 4 to $10 \mathrm{~nm}$, depending on the heat treatment (e.g. [3]). In neutron-irradiated steels, however, $\mathrm{Cu}$ precipitates remain small and $\mathrm{BCC}$ in structure. Together with radiation damage formed by vacancies and self-interstitial atoms, they make a significant contribution to the radiation hardening associated with changes such as loss of ductility and increase of ductile-to-brittle transition temperature (e.g. [4-6]). Interaction between moving dislocations and precipitates is the cause of these effects and understanding of the atomic-scale mechanisms involved is therefore necessary for creation of predictive models of materials properties.

The $\mathrm{Fe}-\mathrm{Cu}$ interatomic potential set in [2] has been widely used because the $\mathrm{Fe}-\mathrm{Fe}$ potential had improvements for several crystal and defect properties over that in the original 


\section{Model}

The modelling method is described in detail in [39]. In summary, the BCC crystal was constructed with $x, y, z$ axes parallel to [111], [ $\overline{1} \overline{1} 2],[1 \overline{1} 0]$. We simulate an infinitely long, straight edge dislocation lying parallel to the $y$-axis with Burgers vector $\boldsymbol{b}=1 / 2[111]$. Periodic boundary conditions were applied along $y$ in order to simulate a row of precipitates 
with centre-to-centre spacing $L$, which equals the model size $L_{\mathrm{y}}$. Values of $L$ in the range 41.4 to $83.6 \mathrm{~nm}$ were considered. In order to avoid restrictions on dislocation movement due to fixed boundary conditions, periodicity was also imposed along $x$, i.e. an array of edge dislocations with period equal to the model size $L_{\mathrm{x}}$ was simulated. Tests were made as in [39] to ensure that $L_{\mathrm{x}}$ was large enough to avoid model-size effects on dislocation behaviour. Values of $L_{\mathrm{x}}$ in the range 30 to $120 \mathrm{~nm}$ were used for the smallest to largest precipitates. The model was bounded by rigid slabs of atoms in the $z$ direction. The size, $L_{z}$, in this direction was $20 \mathrm{~nm}$ for all cases, i.e. the models contained approximately two to eight million atoms. The $\mathrm{Cu}$ precipitates were coherent with the surrounding $\mathrm{BCC}$ matrix of $\mathrm{Fe}$ and as near spherical in shape as possible. Precipitates with diameter, $D$, in the range 0.9 to $6 \mathrm{~nm}$ were modelled: they contained from 59 to $9698 \mathrm{Cu}$ atoms.

Two qualitatively different techniques were used to simulate the dislocation overcoming these obstacles. For MS simulation $(T=0 \mathrm{~K})$, resolved shear strain, $\varepsilon=\varepsilon_{\mathrm{xz}}$, was applied in increments of $10^{-4}$ with relaxation to minimise of the model potential energy at each step. The corresponding resolved shear stress, $\tau=\sigma_{\mathrm{xz}}$, was calculated from the total force exerted by the mobile atoms on the atoms in the rigid slabs at the $z$ boundaries [39]. For the MD simulations $(T>0 \mathrm{~K})$, applied shear strain rate, $\dot{\varepsilon}$, was imposed with values in the range $0.1 \times 10^{6}$ to $50 \times 10^{6} \mathrm{~s}^{-1}$. The time-step was in the range 10 to $2 \mathrm{fs}$ for $T$ in the range 1 to $600 \mathrm{~K}$, and $\tau$ was computed as above. Stress-strain plots were obtained in both the MS and MD studies and the critical shear stress, $\tau_{\mathrm{c}}$, for the dislocation to move through the array of obstacles was determined from the maximum value of $\tau$. Identification and visualisation of the atomic structure of the obstacle and dislocation are important, and analysis of the location of the dislocation core was carried out at each strain increment in MS modelling and every 100 time-steps in MD. The method used is described in [39].

\section{Simulation of strengthening at $T=0 \mathrm{~K}$}

As examples of the dependence of applied stress on strain at $T=0 \mathrm{~K}$, Figure 1 shows $\tau$ versus $\varepsilon$ plots for $L=41.4 \mathrm{~nm}$ and $D$ in the range 1 to $5 \mathrm{~nm}$. (The labels below each curve indicates $D$. For clarity, the graph for $D=6 \mathrm{~nm}$ is not included because the strain required for the dislocation to overcome the obstacle exceeds $2.6 \%$.) The edge dislocation was 
initially a few $\mathrm{nm}$ from the row of precipitates and the plots show that it starts to glide when $\tau$ rises to $24 \mathrm{MPa}$, which is the Peierls stress value for $1 / 2[111](1 \overline{1} 0)$ slip in this model of pure Fe. The dislocation is attracted into a precipitate when close to it, resulting in a reduction in potential energy, despite the fact that a step corresponding to $\boldsymbol{b}$ is created at the $\mathrm{Fe}-\mathrm{Cu}$ interface. The energy change is associated with a lower core energy of the dislocation in $\mathrm{BCC} \mathrm{Cu}$. As a consequence, the plastic strain due to dislocation movement is larger than the imposed strain and $\tau$ is seen to become negative. The dislocation segment inside a precipitate resists further glide and so as $\varepsilon$ continues to increase, the dislocation bows between the precipitates until it breaks away at $\tau_{\mathrm{c}}$.

It is found that the mechanism giving rise to the obstacle resistance of a precipitate changes as $D$ increases. This is reflected in the shape of the stress-strain plot, as seen in Figure 1, and both $\tau_{\mathrm{c}}$ and the line shape at this critical stress. The shapes for $L=62 \mathrm{~nm}$ and values of $D$ up to $5 \mathrm{~nm}$ are shown by visualization of the dislocation core atoms and $\mathrm{Cu}$ atoms on the precipitate surface in Figure 2. The critical line shapes for voids over the same size range are included in the Figure for comparison. The label for each pair of lines indicates from top to bottom: $\tau_{\mathrm{c}}$ for the void, $D$ and $\tau_{\mathrm{c}}$ for the precipitate. (The shape for the $6 \mathrm{~nm}$ precipitate could not be included in Figure 3 at the length scale used because the parallel screw arms at the precipitate surface extend to a length $>100 \mathrm{~nm}$ before breakaway at $\tau_{\mathrm{c}}=292 \mathrm{MPa}$.) The critical angle, $\varphi_{\mathrm{c}}$, subtended by the dislocation segments at the obstacle surface is shown for one of the precipitates. This angle provides an indication of the obstacle strength (see below) and is seen to change from a large value $\left(\sim 170^{\circ}\right)$ for $D=$ $0.9 \mathrm{~nm}$ to $0^{\circ}$ for $D=5 \mathrm{~nm}$, in contrast to a value of $0^{\circ}$ for all but the smallest voids.

Values of $\tau_{\mathrm{c}}$ for precipitates are plotted (triangle symbols) in Figure 3 against the harmonic mean $\left(D^{-1}+L^{-1}\right)^{-1}$ on a $\log$ scale for all the combinations of $D$ and $L$ considered. The units of the ordinate and abscissa are $G b / L$ and $b$, respectively, where $G$ is the elastic shear modulus. The reason for plotting the data in this way is that the following correlation between these quantities was found in the computer-based elasticity treatment with dislocation self-stress included of strengthening by impenetrable obstacles (Orowan strengthening) and voids [40,41]:

$$
\tau_{c}=\frac{G b}{2 \pi L}\left[\ln \left(D^{-1}+L^{-1}\right)^{-1}+\Delta\right]
$$


where $\Delta$ equals 0.77 for the Orowan process and 1.52 for voids. $G$ is chosen by setting $G b^{2} / 4 \pi$ equal to the pre-logarithmic anisotropic energy factor of the screw dislocation of the $1 / 2<111>\{110\}$ system in Fe and is 64GPa [42]. Lines for the two value of $\Delta$ are drawn on Figure 3, which also contains data (circle symbols) for $\tau_{\mathrm{c}}$ for an edge dislocation to overcome a periodic row of spherical voids in the same atomic MS model of Fe as used here $[31,43,44]$. The critical stress values for voids are seen fit equation (1) obtained from the continuum modelling well, except for the smallest size when $D$ falls below $2 \mathrm{~nm}$. For $\mathrm{Cu}$ precipitates, however, the correlation does not apply for $D$ less than $4 \mathrm{~nm}$ and small precipitates are much weaker obstacles than voids of the same size. Only the largest precipitates of the range considered result in $\tau_{\mathrm{c}}$ comparable with that for voids.

The explanation for the $D$ - and $L$-dependence of $\tau_{\mathrm{c}}$ for voids and impenetrable Orowan particles is that they are 'strong' obstacles to dislocation motion and so the dislocation segments at the obstacle surface are pulled into parallel, dipole alignment at $\tau_{\mathrm{c}}$ by the combination of $\tau$ and self-interaction [40,41]. For every obstacle, the forward force, $\tau_{\mathrm{c}} b L$, on the dislocation has to match the dipole tension, i.e. energy per unit length, which is proportional to $\ln (D)$ when $D<<L$ and $\ln (L)$ when $L<<D$, e.g. [45]. Thus, $\tau_{\mathrm{c}} b L$ correlates with $G b^{2} \ln \left(D^{-1}+L^{-1}\right)^{-1}$ and the continuum approximation applies for voids of size down to 1$2 \mathrm{~nm}$.

The significant differences between $\tau_{\mathrm{c}}$ of precipitates and voids for $D$ less than $4 \mathrm{~nm}$ arise because although the potential energy of the crystal is lowered when the dislocation enters a precipitate, the dislocation core energy is not zero in the $\mathrm{Cu}$ and the $\mathrm{Cu}-\mathrm{Fe}$ interface has lower energy than the free-surface step on a void. Consequently, the dislocation is released from the precipitate rather easily and simply shears it without being pulled into screw orientation, as can be seen by the line shapes in Figure 2. For example, the critical included angle, $\varphi_{\mathrm{c}}$, is $70^{\circ}$ for the $3 \mathrm{~nm}$ precipitate compared with $0^{\circ}$ for the void of the same size.

The screw dipole configuration is achieved at $\tau_{\mathrm{c}}$ for $D=4 \mathrm{~nm}$ and the critical line shapes for the precipitate and void are almost indistinguishable for $D \geq 5 \mathrm{~nm}$. The $\tau_{\mathrm{c}}$ values are correspondingly close. The mechanism that controls the process is different for the two obstacles, however. This effect arises from the dependence on $D$ of the stability of the BCC 


\section{Simulation of strengthening at $T>0 \mathrm{~K}$}

As the temperature increases from $0 \mathrm{~K}, \tau_{\mathrm{c}}$ decreases and the dislocation line bows out less in the critical condition. However, the variation with $T$ of the form of the stress-strain curve, the critical line shape and $\tau_{\mathrm{c}}$ depends on $D$, unlike the situation with voids. The dependence of $\tau_{\mathrm{c}}$ on $T$ for all the precipitates sizes and $L=41.4 \mathrm{~nm}$ is plotted in Figure 5. For small precipitates, $\tau_{\mathrm{c}}$ is seen to decrease by $20-30 \%$ between 0 and $100 \mathrm{~K}$, and then by only a further $10-20 \%$ over the next $500 \mathrm{~K}$. (For voids, the changes are approximately twice as much: see Figure 28 of [44].) For the larger precipitates, i.e. those that partially transform to the FCC-like structure at $T=0 \mathrm{~K}$, the decrease in $\tau_{\mathrm{c}}$ is almost constant at approximately $0.2 \mathrm{MPaK}^{-1}$. These dependences stem from differences in the stress-strain plot as $T$ and $D$ are changed. Figure 6 shows the plots for 2,4 and $6 \mathrm{~nm}$ precipitates for the $T$ values 
considered. The shape of the plots is seen is seen to be insensitive to changes in $T$ for small $D$, but to undergo a transition in form with increasing $T$ for larger $D$. The maximum transition occurs at about $100 \mathrm{~K}$ for $D=4$ and $6 \mathrm{~nm}$. No transition occurs for $D=2 \mathrm{~nm}$. This effect is due to the dislocation-induced, partial transformation to the more stable FCC structure reported in the preceding section for $T=0 \mathrm{~K}$.

Confirmation of these trends is to be seen in Figure 7 , which shows the (1 $\overline{1} 0)$ stacking arrangement of $\mathrm{Cu}$ atoms near the equator of the $5 \mathrm{~nm}$ precipitate after the dislocation has broken away at 1, 300 and $600 \mathrm{~K}$ : it should be compared with the low temperature structures for $D=4$ and $6 \mathrm{~nm}$ in Figure 4. The region of transformed $\mathrm{Cu}$ in the $5 \mathrm{~nm}$ precipitate reduces with increasing $T$ until it barely exists at $600 \mathrm{~K}$. Mixed climb of the edge dislocation as it breaks for a precipitate is another signature of the transformation process. It was seen in the line shapes for 3 and $4 \mathrm{~nm}$ precipitates in [31,32]. The extent of climb is shown by the dislocation core configurations for $5 \mathrm{~nm}$ precipitates across the range of temperature in Figure 8. These [111] projections of the core show the bottom of the extra half plane after the dislocation has broken away from the precipitate. There is clearly a stronger tendency for climb with decreasing $T$, i.e. with increasing volume fraction of transformed $\mathrm{Cu}$. Climb is almost absent at $600 \mathrm{~K}$. Although both climb up and climb down occur, the net effect is climb down, indicating that the transformation is assisted by creation of vacancies within a precipitate. Climb associated with the structural transformation within $\mathrm{Cu}$ precipitates contrasts with climb associated with edge dislocation breakaway from voids. In the latter case, the dislocation climbs up by absorbing vacancies from the void and this process occurs for voids of all sizes and at all temperatures in studies by MS and MD, e.g. $[31,43.44]$.

When a precipitate is large enough ( $D=6 \mathrm{~nm}$ here), dislocation-induced structural transformation of the $\mathrm{Cu}$ occurs over the whole temperature range from 0 to $600 \mathrm{~K}$, although the extent of transformation still depends on $T$. This effect has been quantified by identifying the $\mathrm{Cu}$ precipitate atoms whose neighbour coordination is closer to FCC than BCC. (Typically, these atoms have fewer than five BCC neighbours.) The temperature dependence of the fraction of atoms transformed into FCC-like structure in a $6 \mathrm{~nm}$ precipitate is plotted in Figure 9. The fraction of transformed atoms increases to its maximum of 0.55 between 0 and $100 \mathrm{~K}$ and then declines to 0.1 at $600 \mathrm{~K}$. The increase at low $T$ is believed to reflect the influence on atom mobility of thermal energy. The atomic 


\section{Discussion}

The interatomic potentials of F-S type developed in [2] for the $\mathrm{Fe}-\mathrm{Cu}$ system have proved to be valuable for many simulation studies of phenomena associated with the creation of radiation damage and changes in mechanical properties in pure $\mathrm{Fe}$ and $\mathrm{Fe}-\mathrm{Cu}$ alloys, as is clear from the number of citations it has received $(257$ at the time of writing $-29.5 .09)$. In the present paper, we have focused on the obstacle resistance nano-scale $\mathrm{Cu}$ precipitates provide to dislocation glide in Fe. The technological relevance of this has been referred to in section 1. It has been seen that modelling based on this interatomic potential predicts a strengthening effect due to a dislocation-induced structural transformation of precipitates that are initially coherent with the surrounding BCC matrix of Fe. This transformation effect was first revealed in MS modelling of a screw dislocation threading $\mathrm{Cu}$ precipitates [46]. The size dependence of the $\mathrm{Cu}$ transformation mechanism due to screw dislocations has been investigated more recently by MD simulation of screw-precipitate interaction at $10 \mathrm{~K}$ under constant $\tau$ [49]. It was observed that the phase transformation occurred for $D>1.8 \mathrm{~nm}$ and 
that when $D$ exceeds $2.5 \mathrm{~nm}$ the dislocation bypass mechanism becomes Orowan looping due to the coherency loss of the precipitates. Values of $\tau_{\mathrm{c}}$ were not obtained.

In the present paper, we have extended the data for $\tau_{\mathrm{c}}$ reported earlier [31,32] in order to cover a wider range of $D$ and $T$ values and thereby investigate the conditions under which the transformation mechanism is realised. The transformation is due to the difference in the cohesive energy of FCC and BCC copper. However, the thermodynamic driving force for the transformation is small at high temperature and insufficient to provide the energy for loss of coherency for small precipitates. The strengthening effect due to the transformation is therefore realised only for large $D$ and low $T$ in the spectra of size and temperature. The simulations suggest that the yield stress of an under-aged or neutron-irradiated $\mathrm{Fe}-\mathrm{Cu}$ alloy containing small, coherent precipitates should have a weak $T$-dependence, whereas the dependence should be stronger in an over-aged or electron-irradiated alloy where the population of coherent precipitates has larger size.

We have referred to strengthening by voids several times in the preceding sections. A final comparison with $\mathrm{Cu}$ precipitates illustrates very clearly how the availability of suitable interatomic potentials leads to insight into atomic-scale mechanisms. Figure 12 compares the $T$-dependence of $\tau_{\mathrm{c}}$ for 2,4 and $6 \mathrm{~nm}$ voids and precipitates. The nearcoincidence of the curves for $D=6 \mathrm{~nm}$ shows that despite the totally different nature of the obstacles, they are both 'strong' and $\tau_{\mathrm{c}}$ is determined by the screw dipole arrangement of the dislocation before breakaway occurs. For $D=4 \mathrm{~nm}$, precipitates are weaker obstacles than voids at all $T$. The difference increases with decreasing size and when $D=2 \mathrm{~nm}$ the critical stress for precipitates is only about half that of voids at all temperatures, demonstrating that the energy of the step formed on the $\mathrm{Fe}-\mathrm{Cu}$ interface and the effect of $\mathrm{BCC} \mathrm{Cu}$ on the dislocation core energy are not sufficient to stop the dislocation cutting through the precipitate well before the dipole configuration is achieved.

The results described here were obtained for an applied strain rate $\dot{\varepsilon}=5 \times 10^{6} \mathrm{~s}^{-1}$, but it should be noted that the conclusions drawn are valid across the range of $\dot{\varepsilon}$ that can be used for MD models with millions of atoms. This is shown in Figure 13 by data for $\tau_{\mathrm{c}}$ versus $\dot{\varepsilon}$ for 2 and $6 \mathrm{~nm}$ precipitates at $T=300 \mathrm{~K}$. The range over several orders of magnitude of $\dot{\varepsilon}$ is the widest that has been reported for simulation of dislocation-obstacle interactions. Figure 13 shows that the influence of obstacle size on $\tau_{\mathrm{c}}$ is almost independent of $\dot{\varepsilon}$. In addition, the data indicate that when the strain rate applied in simulations is less than about $5 \times 10^{6} \mathrm{~s}^{-1}$, 
the critical stress for these obstacles is independent of $\dot{\varepsilon}$. This limit corresponds to a dislocation velocity in steady state free flight of about $25 \mathrm{~ms}^{-1}$ for the model sizes used here.

It is reassuring to point out that direct experimental evidence in support of the predictions from simulation of the influence of $D$ and $T$ on stability of $\mathrm{Cu}$ precipitates during plastic deformation has been obtained by Lozano-Perez et al. [50] by utilising the crystallography of the $\mathrm{BCC} \rightarrow 9 \mathrm{R}$ martensitic transformation. Planes of atoms in twinned 9R precipitates exhibit characteristic 'herring-bone' fringe contrast when viewed along a <111> direction of the Fe matrix in a high-resolution electron microscope (HREM). The angle, $\alpha$, between fringes in neighbouring twin bands is approximately $129^{\circ}$ immediately after the transformation, but relaxes during annealing to $121^{\circ}$ to reduce the strain energy [51]. Samples of a $\mathrm{Fe}-1.3 \mathrm{wt} \% \mathrm{Cu}$ alloy were aged at $550^{\circ} \mathrm{C}$ before cooling to room temperature, in order that precipitates larger than about $5 \mathrm{~nm}$ would transform to $9 \mathrm{R}$ whilst smaller precipitates would retain the BCC structure. One set of samples was plastically deformed by bending at room temperature and both sets were then annealed at $400^{\circ} \mathrm{C}$ to allow transformed precipitates to relax. HREM foils were prepared at $-60^{\circ} \mathrm{C}$ so that any remaining untransformed precipitates should transform to 9R. Angle $\alpha$ was then measured for precipitates in both sets of samples. The results for $\alpha$ versus $D$ plotted in Figure 3 of [50] show that precipitates in the undeformed alloy have a relaxation threshold of about 4-5 nm, while all the precipitates in the deformed samples appear to be relaxed. It may be noted that the set of the interatomic potentials used here results in a similar threshold, for the lowtemperature transformation was only observed in precipitates with $D$ above $4 \mathrm{~nm}$ diameter.

Finally, we re-emphasise that a condition for the dislocation-induced transformation mechanism of strengthening discussed here is that the material of the precipitate is metastable when coherent with the surrounding matrix. (Thus, in high-chromium $(\mathrm{Cr})$ ferritic/martensitic steels, Cr-rich $\alpha^{\prime}$ phase separates from the $\alpha$ phase and forms a fine dispersion of nano-scale obstacles to dislocation motion. Unlike $\mathrm{Cu}$ in $\mathrm{Fe}, \mathrm{Cr}$ is stable in the BCC structure and the strengthening mechanism is different, as demonstrated in the simulations in [52].) Furthermore, the $\mathrm{Fe}-\mathrm{Cu}$ results show that the energy difference between the metastable and stable structures of the precipitate must not be so large that the transformation occurs without the intervention of a dislocation. 


\section{Conclusions}

(a) The availability of a set of interatomic potentials of Finnis-Sinclair form for the $\mathrm{Fe}-\mathrm{Cu}$ system has allowed simulation of edge dislocation- $\mathrm{Cu}$ precipitate interaction in $\mathrm{Fe}$ to be carried out with models containing millions of atoms for a wide range of temperature and applied strain rate.

(b) The simulations reveal that the atomic-scale mechanism that controls the obstacle strength of a precipitate depends on the precipitate size $D$ and ambient temperature $T$.

(c) The dislocation overcomes small precipitates $(D \leq 2-3 \mathrm{~nm})$ at all temperatures by a simple shear mechanism. This results in relatively low critical stress, $\tau_{\mathrm{c}}$, for dislocation breakaway. $\tau_{\mathrm{c}}$ for these precipitates has a strong temperature dependence of over the range where edge dislocation glide is thermally-activated $(T<$ approx. $100 \mathrm{~K})$ and a weak dependence above that.

(d) Larger precipitates may transform from the BCC to an FCC-like structure if $T$ is low enough. This effect increases $\tau_{\mathrm{c}}$ and results in a critical dislocation shape similar to that of Orowan strengthening, i.e. characterized by zero breaking angle at $\tau_{\mathrm{c}}$, but without creation of an Orowan dislocation loop around the precipitate.

(e) The thermodynamic driving force for the transformation increases with decreasing temperature. However, the surrounding BCC Fe matrix restricts the transformation and this effect lessens with increasing $D$. Thus, the critical dislocation shape and $\tau_{\mathrm{c}}$ exhibit the interplay between $T$ and $D$, such that even large precipitates are weak obstacles at high $T$.

(f) The dislocation-induced transformation effects are clearly seen in visualisations of the stacking sequence and FCC-like neighbour coordination of $\mathrm{Cu}$ atoms after dislocation breakaway.

(g) The effects found by simulation are consistent with the results of HREM experiments on deformed $\mathrm{Fe}-\mathrm{Cu}$ alloy reported in [50].

(h) The results presented for the dislocation-precipitate interaction mechanism and its dependence on $T$ and $D$ imply that the temperature dependence of the yield stress of underaged or neutron-irradiated $\mathrm{Fe}-\mathrm{Cu}$ alloys should be different from that of over-aged or electron-irradiated alloys. 


\section{Acknowledgements}

This work was supported by the Division of Materials Sciences and Engineering and the Office of Fusion Energy Sciences, U.S. Department of Energy, under contract DE-AC0500OR22725 with UT-Battelle, LLC; and grant GR/R68870/01 from the UK Engineering and Physical Sciences Research Council. 


\section{References}

1. M.W. Finnis and J.E. Sinclair, Phil. Mag. A 53 (1984) p.45.

2. G.J. Ackland, D.J. Bacon, A.F. Calder and T. Harry, Phil. Mag. A 75 (1997) p.713.

3. R. Monzen, M.L. Jenkins, A.P. Sutton, Philos. Mag. A 80 (2000) p.711.

4. J.T. Buswell, C.A. English, M.G. Hetherington, W.J. Phythian, G.D.W. Smith, G.M. Worral, Effects of Radiation on Materials: 14th Int. Sympos. ASTM STP 1046, vol. II, ASTM, Philadelphia, PA, 1990, p.127.

5. R.G. Carter, N. Soneda, K. Dohi, J.M. Hyde, C.A. English, W.L. Server, J. Nucl. Mater. 298 (2001) p.211.

6. R. Chaouadi, R. Gerard, J. Nucl. Mater. 345 (2005) p.65.

7. G.J. Ackland, G. Tichy, V. Vitek and M.V. Finnis, Phil. Mag. A 56 (1987) p.735.

8. A.F. Calder and D.J. Bacon, in Microstructure Evolution During Irradiation (eds. I.M. Robertson, G.S. Was, L.W. Hobbs and T. Diaz de la Rubia), MRS Sympos. Proc. vol. 439 (1997) p. 521.

9. D.J. Bacon, Yu.N. Osetsky and R.E. Stoller, J. Nucl. Mater. 323 (2003) p.152.

10. C.S. Becquart, C. Domain, A. Legris, J.C. Van Duysen, J. Nucl. Mater. 280 (2000) p.73.

11. A. Souidi, C.S. Becquart, C. Domain, D. Terentyev, L. Malerba, A.F. Calder, D.J. Bacon, R.E. Stoller, Yu.N. Osetsky and M. Hou, J. Nucl. Mater. 355 (2006) p.89.

12. A.F. Calder, D.J. Bacon, A.V. Barashev and Yu.N. Osetsky, Phil. Mag. Lett. 88 (2008) p.43.

13. Yu.N. Osetsky, M. Victoria, A. Serra, S.I. Golubov and V. Priego, J. Nucl. Mater. 251 (1997) p.34.

14. A.V. Barashev, Yu.N. Osetsky and D.J. Bacon, Philos. Mag. 80 (2000) p.2709.

15. Yu.N. Osetsky, A. Serra and V. Priego, J. Nucl. Mater. 276 (2000) p.202.

16. M.A. Puigvi, Yu.N. Osetsky and A. Serra, Philos. Mag. 83 (2003) p.857.

17. Yu.N. Osetsky, D.J. Bacon and A. Serra, Philos. Mag. 83 (2003) p.61.

18. F. Gao, H. Heinisch, R.J. Kurtz, Yu.N. Osetsky and R.G. Hoagland, Philos. Mag. 85 (2005) p.619.

19. J. Marian, B.D. Wirth, J.M. Perlado, G.R. Odette and T. Diaz de la Rubia, Phys. Rev. B 64 (2001) 094303. 
20. J. Marian, B.D. Wirth, A. Caro, B. Sadigh, G.R. Odette, J.M. Perlado and T. Diaz de la Rubia, Phys. Rev. B 65 (2002) 144102.

21. J. Marian, B.D. Wirth, G.R. Odette and J.M. Perlado, Comput. Mater. Sci. 31 (2004) p.347.

22. Yu.N. Osetsky, A. Serra, M. Victoria, S.I. Golubov and V. Priego, Phil. Mag. 79 (1999) p.2259; ibid: p.2285.

23. Yu.N. Osetsky, D.J. Bacon and V. Mohles, Phil. Mag. 83 (2003) p.3623.

24. Yu.N. Osetsky and D.J. Bacon, J. Nucl. Mater. 323 (2003) p.268.

25. Yu.N. Osetsky and D.J. Bacon, Mater. Sci. Eng. A 400-401 (2005) p.374.

26. D. Terentyev, D.J. Bacon and Yu.N. Osetsky, J. Phys. Condens. Matter 20 (2008) p.445007.

27. D.J. Bacon, Yu.N. Osetsky and Z. Rong, Phil. Mag. 86 (2006) p.3921.

28. D. Terentyev, P. Grammatikopoulos, D.J. Bacon, Yu. N. Osetsky, Acta Mater. 56 (2008) p.5034.

29. Yu.N. Osetsky, D. Rodney and D.J. Bacon, Philos. Mag. 86 (2006) p.2295.

30. Yu.N. Osetsky, Y. Matsukawa, and R.E. Stoller, J. Nucl. Mater. 329 (2004) p. 1228.

31. Yu.N. Osetsky, D.J. Bacon and V. Mohles, Phil. Mag. 83 (2003) p.3623.

32. D.J. Bacon and Y.N. Osetsky, J. Nucl. Mater. 329-333 (2004) p.1233.

33. J.J. Blackstock and G. J. Ackland, Philos. Mag. A, 81 (2001) p.212.

34. A. Machov, Comput. Mater. Sci. 24 (2002) p.535.

35. A.C. Arokiam, A.V. Barashev, D.J. Bacon and Yu.N. Osetsky, Philos. Mag. Lett. 85 (2005) p.491.

36. D. Kulikov, L. Malerba and M. Hou, Philos. Mag. 86 (2006) p.141.

37. M. Ludwig, D. Farkas, D. Pedraza and S. Schmauder, Modelling Simul. Mater. Sci. Eng. 6 (1998) p.19.

38. G.J. Ackland, M.I. Mendelev, D.J. Srolovitz, S. Han et al., J. Phys. Condens. Matter 16 (2004) S2629.

39. Yu.N. Osetsky and D.J. Bacon, Modelling Simul. Mater. Sci. Eng. 11 (2003) p.427.

40. D.J. Bacon, U.F. Kocks and R.O. Scattergood, Phil. Mag. 28 (1973) p.1241.

41. R.O. Scattergood and D.J. Bacon, Acta Metall. 30 (1982) p.1665.

42. D.J. Bacon, in Fundamentals of Deformation and Fracture (eds B.A. Bilby, K.J. Miller and J.R. Willis), Cambridge University Press (1985) p.401. 
43. D.J. Bacon and Yu.N. Osetsky, Math. Mech. Solids 14 (2009) p.270.

44. D.J. Bacon, Yu.N. Osetsky and D. Rodney, in Dislocations in Solids (eds. J.P. Hirth and L. Kubin), Elsevier, Amsterdam (2009) chap. 88, vol.15, in the press.

45. D. Hull and D.J. Bacon, Introduction to Dislocations, Butterworth-Heinemann, Oxford, 2001.

46. T. Harry and D.J. Bacon, Acta Mater. 50 (2002a) p.195; (2002b) p.209.

47. K.C. Russell and L.M. Brown, Acta Metall. 20 (1972) p.969.

48. Yu.N. Osetsky and D.J. Bacon, J. Nucl. Mater. 323 (2003) p.268.

49. J.H. Shim, Y.W. Cho, S.C. Kwon, W.W. Kim, B.D. Wirth, Appl. Phys. Lett. 90 (2007) p.021906.

50. S. Lozano-Perez, M.L. Jenkins, J.M. Titchmarsh, Philos. Mag. Lett. 86 (2006) p.367.

51. R. Monzen, M.L. Jenkins and A.P. Sutton, Philos. Mag. A 80 (2000) p.711.

52. D.A. Terentyev, G. Bonny, L. Malerba, Acta Mater. 56 (2008) p.3229. 


\section{Figure captions}

Fig. 1. Stress-strain curves obtained for interaction between an edge dislocation and $\mathrm{Cu}$ precipitates with spacing $L=41.4 \mathrm{~nm}$ and diameter $D$ as indicated in Fe at $0 \mathrm{~K}$.

Fig. 2. Critical line shape in the $(1 \overline{1} 0)$ slip plane for a dislocation passing a row of either spherical voids or $\mathrm{Cu}$ precipitates with $L=62 \mathrm{~nm}$ and $D$ in the range $0.9-5 \mathrm{~nm}$ size in Fe at $0 \mathrm{~K}$. Black line: shape for voids; grey line: shape for precipitates. The labels for each pair of shapes indicate: $\tau_{\mathrm{c}}$ for void, $D$ and $\tau_{\mathrm{c}}$ for precipitate, in descending order.

Fig. 3. Critical stress $\tau_{\mathrm{c}}$ (units $G b / L$ ) versus the harmonic mean of $D$ and $L$ (unit $b$ ) for voids (circles) and $\mathrm{Cu}$ precipitates (triangles) in Fe at $0 \mathrm{~K}$ for all the values of $D(0.9$ $6 \mathrm{~nm}$ ) and $L(41.4-83.6 \mathrm{~nm})$ considered. Lines found in [40.41] to be best fits to $\tau_{\mathrm{c}}$ values obtained in continuum modelling for voids and impenetrable Orowan particles are also shown.

Fig. 4. Position of $\mathrm{Cu}$ atoms in four consecutive $(1 \overline{1} 0)$ planes through the centre of a precipitate in Fe after dislocation breakaway. (a) $4 \mathrm{~nm}$ precipitate at $0 \mathrm{~K}$; (b) $6 \mathrm{~nm}$ precipitate at $10 \mathrm{~K}$.

Fig. 5. Plot of $\tau_{\mathrm{c}}$ versus $T$ for $\mathrm{Cu}$ precipitates in Fe. $D$ is as indicated, $L=41.4 \mathrm{~nm}$ and $\dot{\varepsilon}=$ $5 \times 10^{6} \mathrm{~s}^{-1}$.

Fig. 6. Stress-strain curves for interaction between an edge dislocation and $\mathrm{Cu}$ precipitates with spacing $L=41.4 \mathrm{~nm}$ in Fe strained at $5 \times 10^{6} \mathrm{~s}^{-1}$. (a) $D=2 \mathrm{~nm}$ and $T=1$ to $450 \mathrm{~K}$; (b) $D=4 \mathrm{~nm}$ and $T=1$ to $450 \mathrm{~K}$; (c) $D=6 \mathrm{~nm}$ and $T=1$ to $600 \mathrm{~K}$.

Fig. 7. Position of $\mathrm{Cu}$ atoms in four consecutive $(1 \overline{1} 0)$ planes through the centre of a $5 \mathrm{~nm}$ precipitate in Fe after dislocation breakaway at (a) $1 \mathrm{~K}$, (b) $300 \mathrm{~K}$ and (c) $600 \mathrm{~K}$.

Fig. 8. Core of the edge dislocation line in [111] projection after breakaway from a $5 \mathrm{~nm}$ $\mathrm{Cu}$ precipitate in $\mathrm{Fe}$ at the temperatures indicated. Climb up indicates absorption of vacancies from the precipitate whereas climb down is due to creation of vacancies in the precipitate.

Fig.9. Temperature-dependence of the fraction of the atoms transformed into FCC-like structure in $6 \mathrm{~nm}$ precipitate after dislocation breakaway. 
Fig.10. Configuration of the atoms transformed into FCC-like structure inside a $6 \mathrm{~nm}$ precipitate after dislocation breakaway at (a) $10 \mathrm{~K}$, (b) $100 \mathrm{~K}$ (maximum transformed fraction) and (c) $600 \mathrm{~K}$.

Fig. 11. Critical line shape in the $(1 \overline{10})$ plane for a dislocation passing a row of (a) $2 \mathrm{~nm}$ and (b) $4 \mathrm{~nm} \mathrm{Cu}$ precipitates with spacing $41.4 \mathrm{~nm}$ in Fe at the temperature indicated.

Fig. 12. Plots of $\tau_{\mathrm{c}}$ versus $T$ for $\mathrm{Cu}$ precipitates and voids in $\mathrm{Fe}$ for $D=2,4$ and $6 \mathrm{~nm}$, as indicated. $L=41.4 \mathrm{~nm}$ and $\dot{\varepsilon}=5 \times 10^{6} \mathrm{~s}^{-1}$.

Fig. 13. Variation of $\tau_{\mathrm{c}}$ with applied strain rate for 2 and $6 \mathrm{~nm} \mathrm{Cu}$ precipitates (triangles) and voids (circles) in Fe at $300 \mathrm{~K}$. The dislocation velocity, $V_{\mathrm{d}}$, in steady state flight depends on the model size through the Orowan relation between $\dot{\varepsilon}, V_{\mathrm{d}}$ and dislocation density [45]. For the lowest value $\dot{\varepsilon}=10^{5} \mathrm{~s}^{-1}$ here, $V_{\mathrm{d}}=0.5 \mathrm{~ms}^{-1}$, as indicated. 


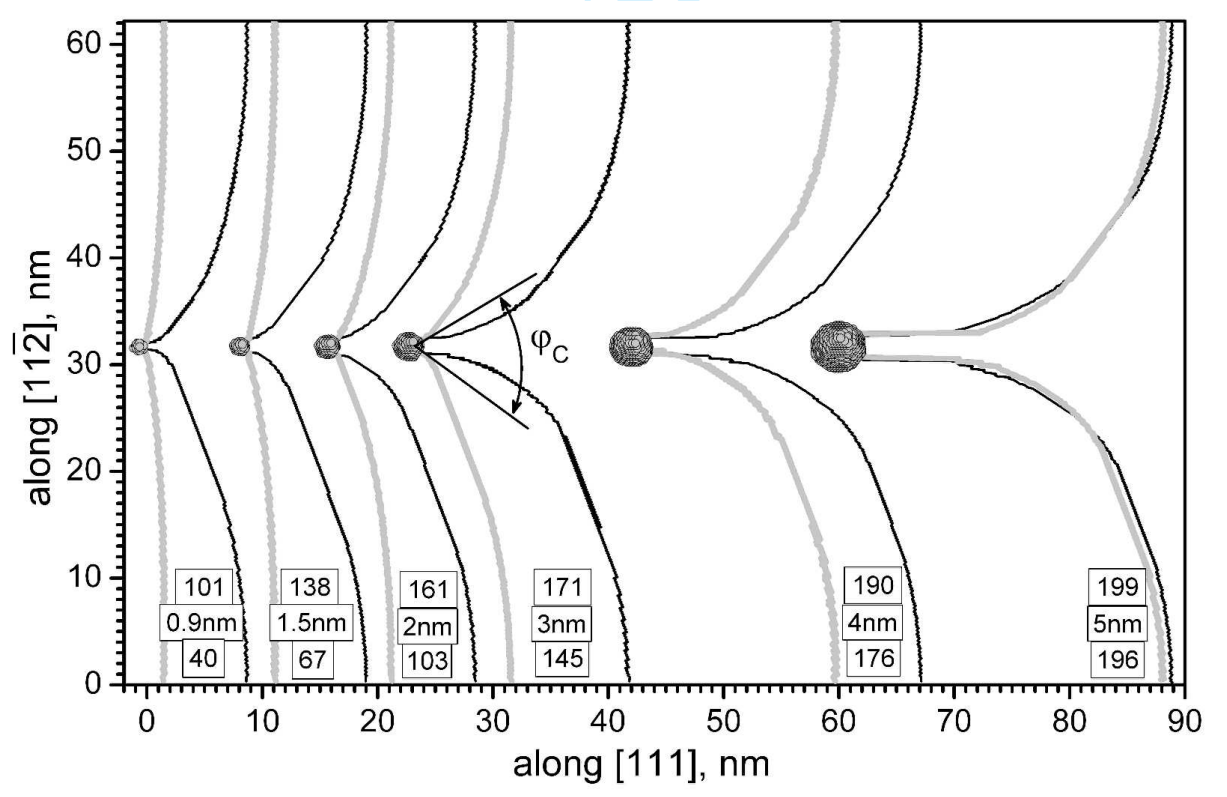

Fig. 2. Critical line shape in the $(1 \overline{1} 0)$ slip plane for a dislocation passing a row of either spherical voids or $\mathrm{Cu}$ precipitates with $L=62 \mathrm{~nm}$ and $D$ in the range $0.9-5 \mathrm{~nm}$ size in Fe at $0 \mathrm{~K}$. Black line: shape for voids; grey line: shape for precipitates. The labels for each pair of shapes indicate: $\tau_{\mathrm{c}}$ for void, $D$ and $\tau_{\mathrm{c}}$ for precipitate, in descending order. 


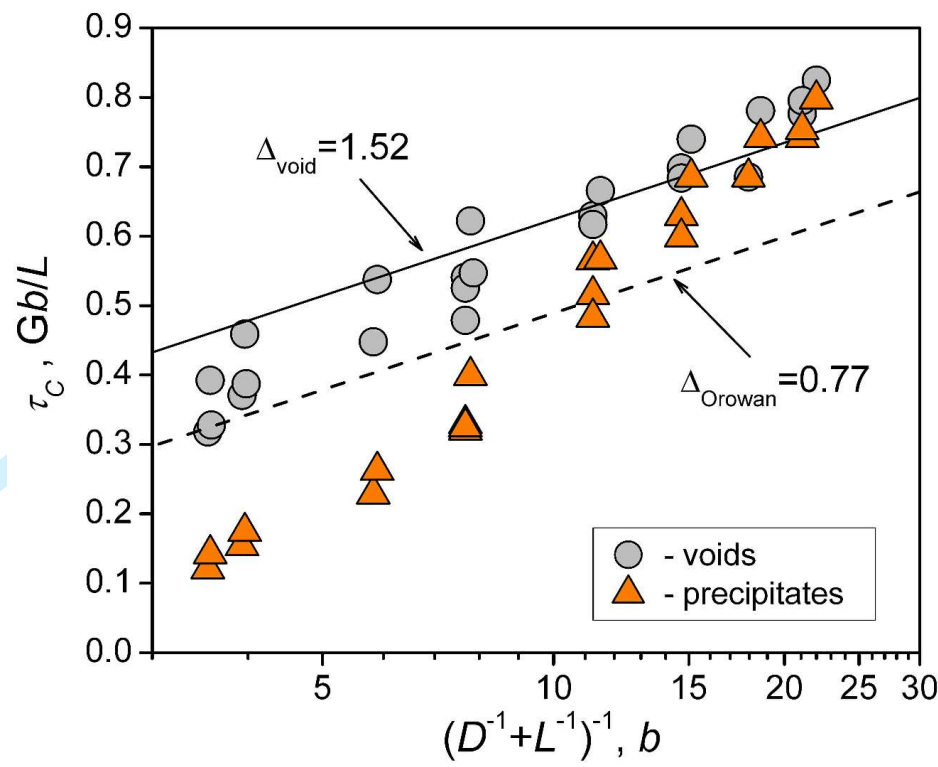

Fig. 3. Critical stress $\tau_{\mathrm{c}}$ (units $G b / L$ ) versus the harmonic mean of $D$ and $L$ (unit $b$ ) for voids (circles) and $\mathrm{Cu}$ precipitates (triangles) in $\mathrm{Fe}$ at $0 \mathrm{~K}$ for all the values of $D(0.9-6 \mathrm{~nm})$ and $L$ (41.4$83.6 \mathrm{~nm})$ considered. Lines found in [40.41] to be best fits to $\tau_{\mathrm{c}}$ values obtained in continuum modelling for voids and impenetrable Orowan particles are also shown.
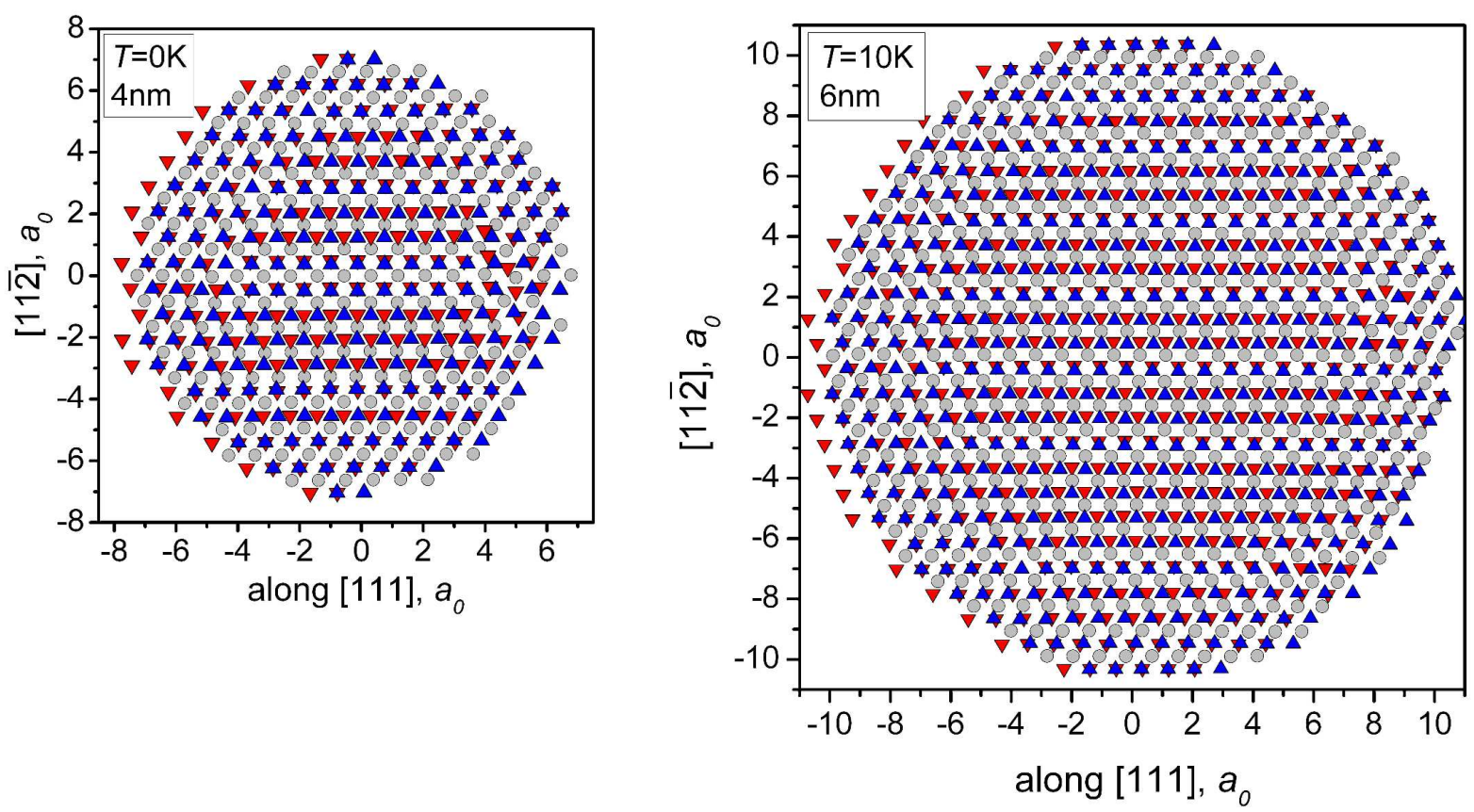

Fig. 4. Position of $\mathrm{Cu}$ atoms in four consecutive $(1 \overline{1} 0)$ planes through the centre of a precipitate in $\mathrm{Fe}$ after dislocation breakaway. (a) $4 \mathrm{~nm}$ precipitate at $0 \mathrm{~K}$; (b) $6 \mathrm{~nm}$ precipitate at $10 \mathrm{~K}$. 


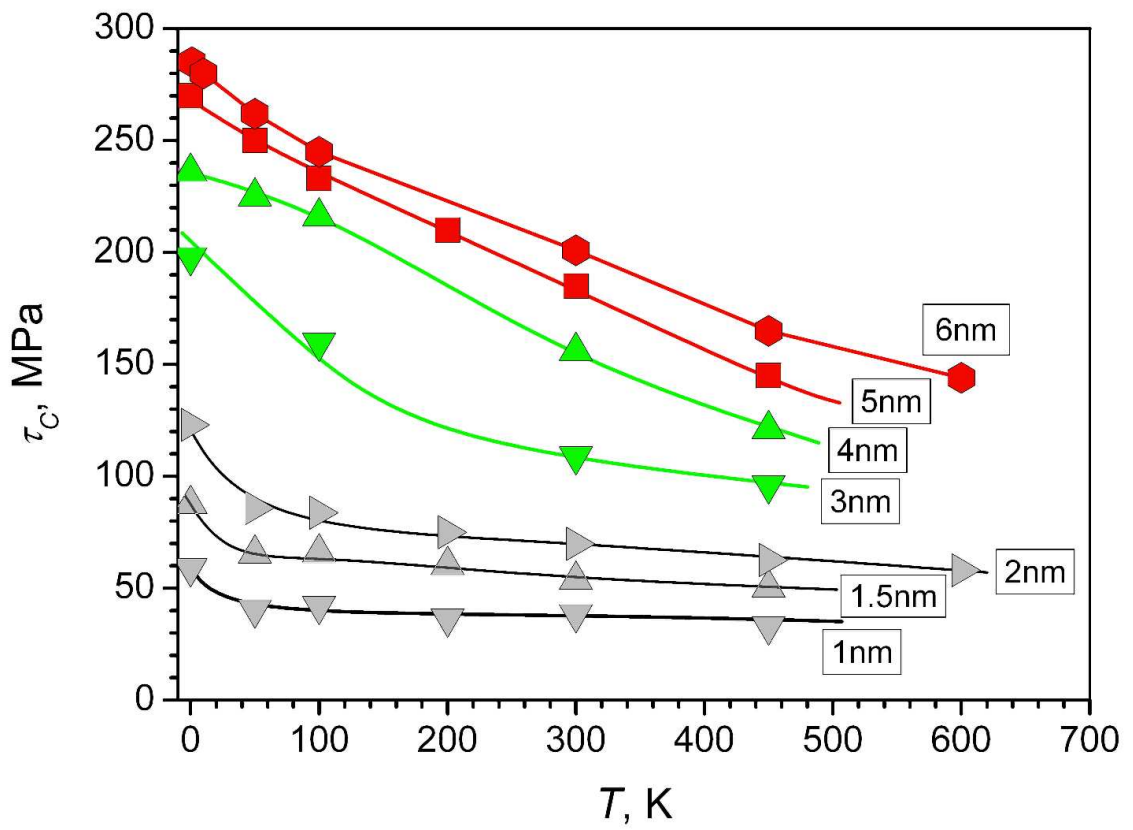

Fig. 5. Plot of $\tau_{\mathrm{c}}$ versus $T$ for $\mathrm{Cu}$ precipitates in Fe. $D$ is as indicated, $L=41.4 \mathrm{~nm}$ and $\dot{\varepsilon}=5 \times 10^{6} \mathrm{~s}^{-1}$. 


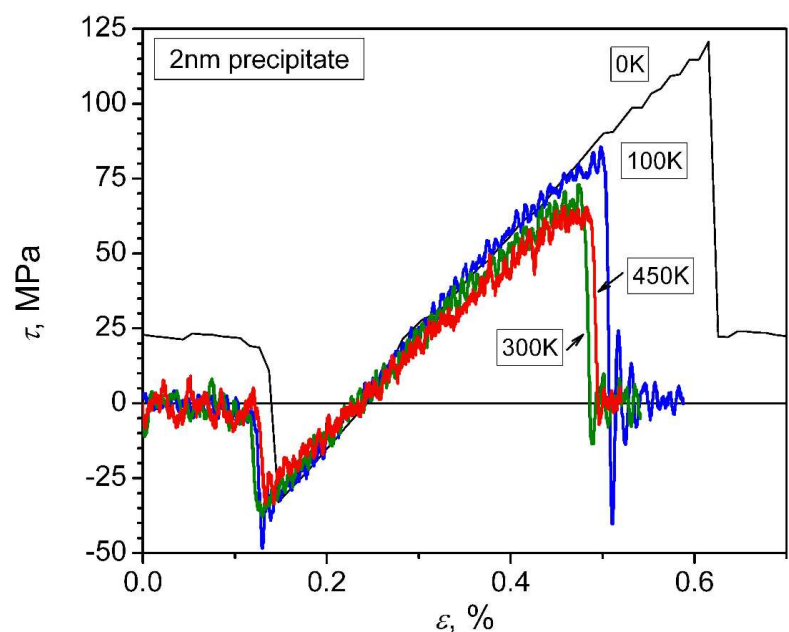

(a)

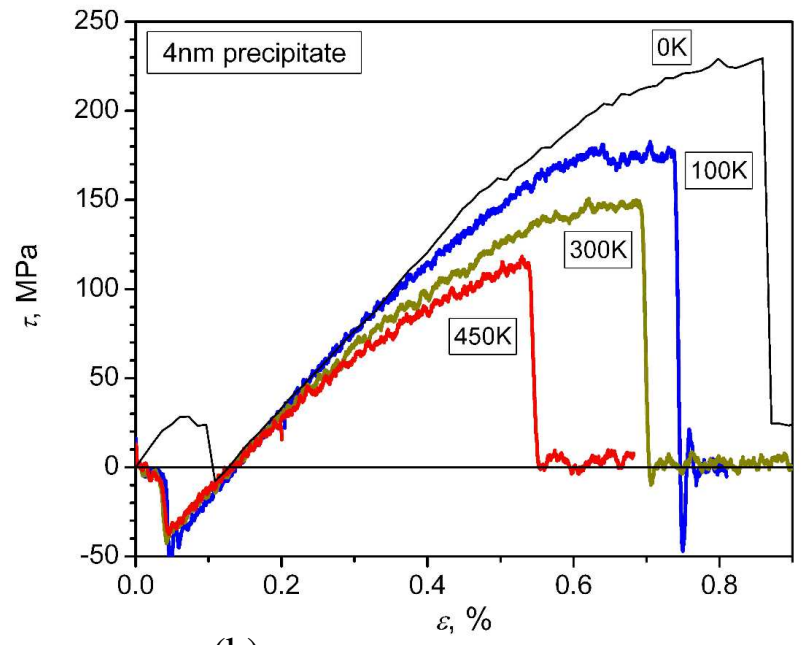

(b)

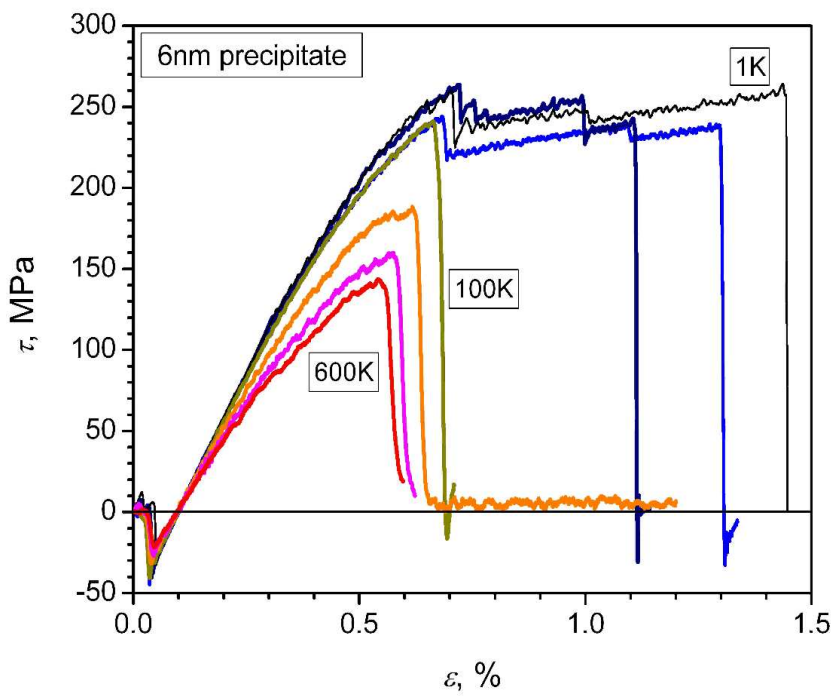

(c)

Fig. 6. Stress-strain curves for interaction between an edge dislocation and $\mathrm{Cu}$ precipitates with spacing $L=41.4 \mathrm{~nm}$ in Fe strained at $5 \times 10^{6} \mathrm{~s}^{-1}$. (a) $D=2 \mathrm{~nm}$ and $T=1$ to $450 \mathrm{~K}$; (b) $D=4 \mathrm{~nm}$ and $T=1$ to $450 \mathrm{~K}$; (c) $D=6 \mathrm{~nm}$ and $T=1$ to $600 \mathrm{~K}$. 


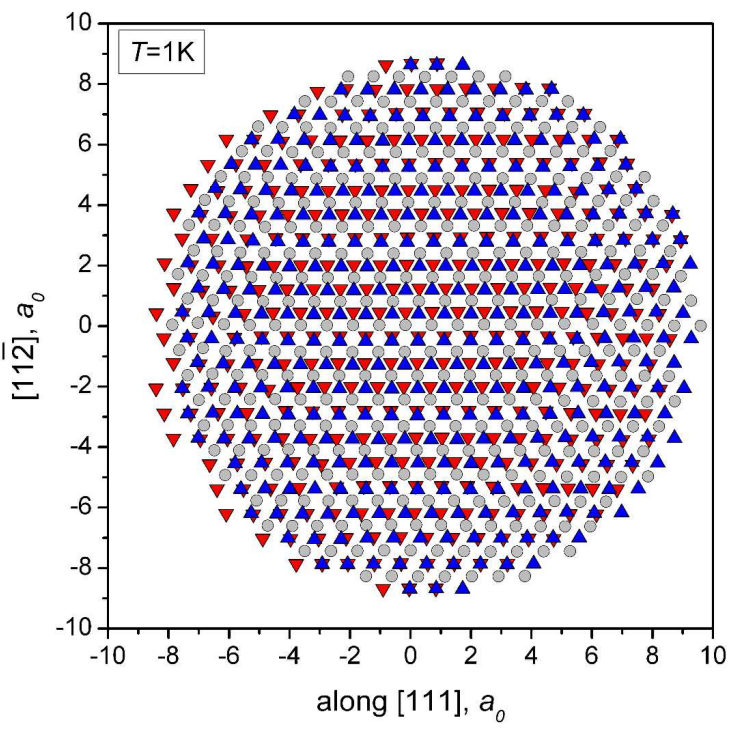

(a)

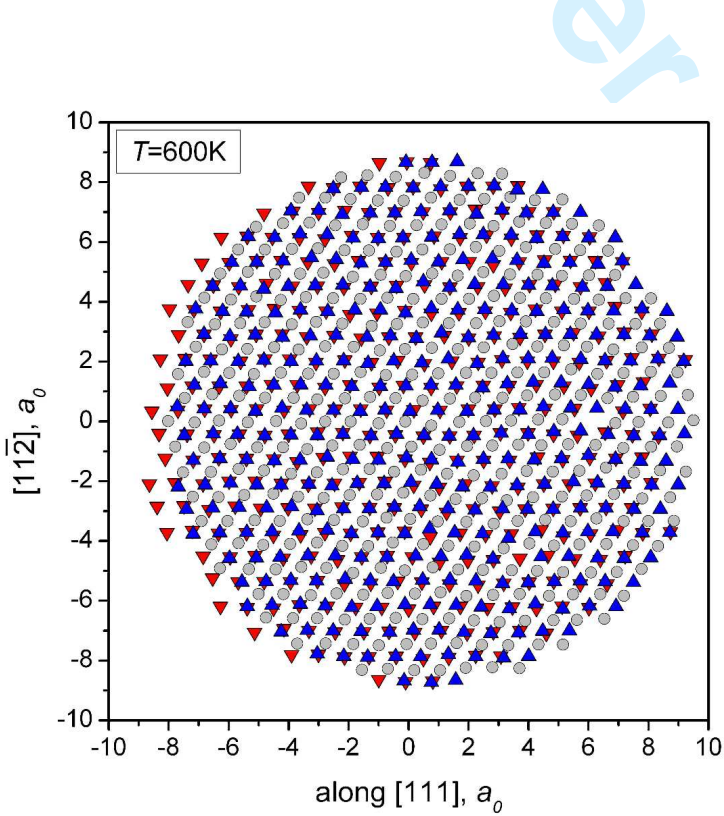

(c)

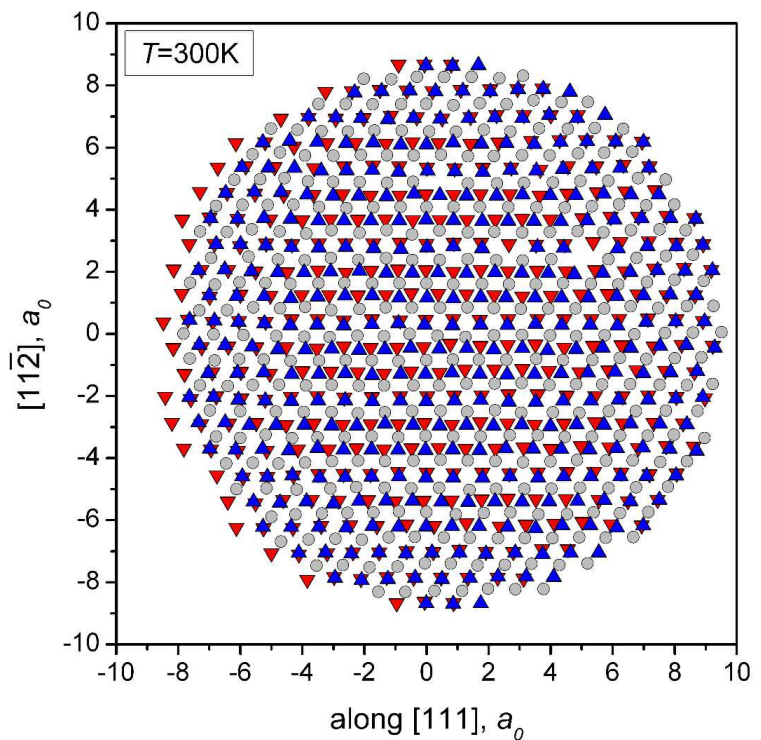

(b)

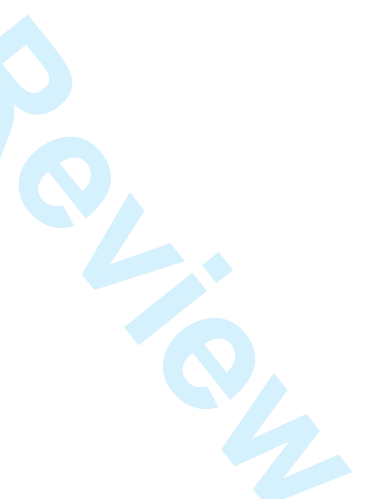

Fig. 7. Position of $\mathrm{Cu}$ atoms in four consecutive $(1 \overline{1} 0)$ planes through the centre of a $5 \mathrm{~nm}$ precipitate in Fe after dislocation breakaway at (a) $1 \mathrm{~K}$, (b) $300 \mathrm{~K}$ and (c) $600 \mathrm{~K}$. 


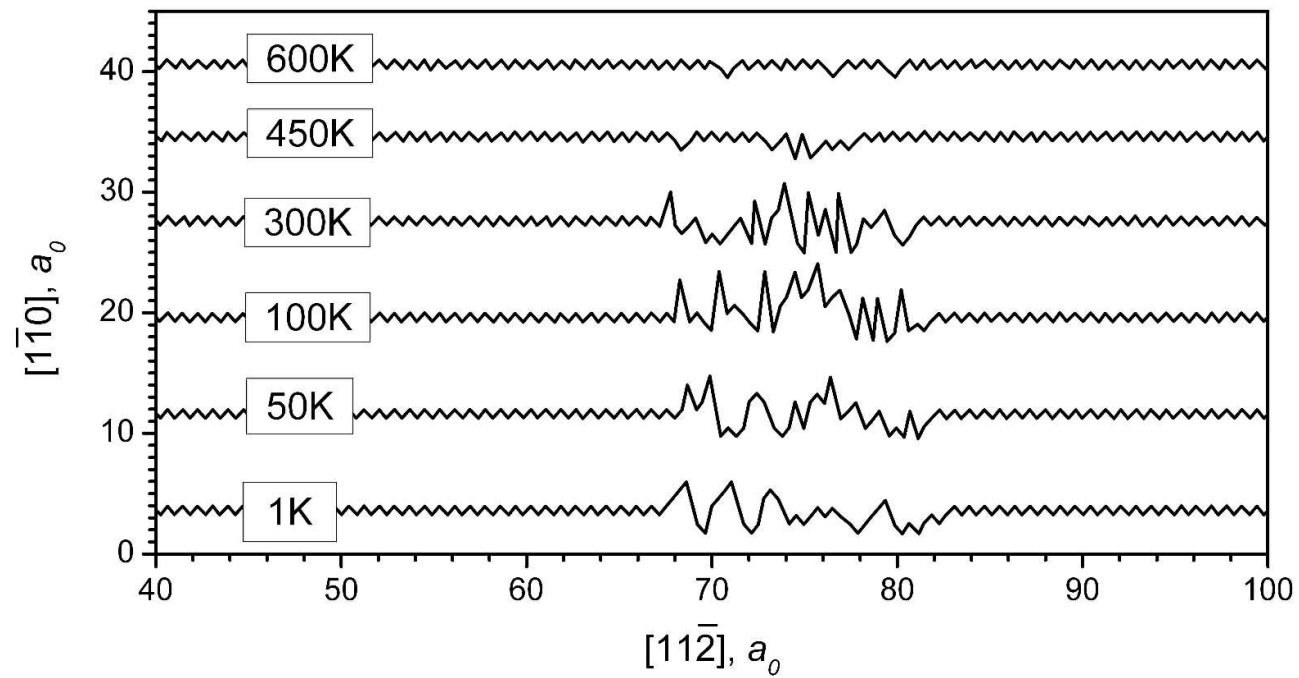

Fig. 8. Core of the edge dislocation line in [111] projection after breakaway from a $5 \mathrm{~nm}$ Cu precipitate in $\mathrm{Fe}$ at the temperatures indicated. Climb up indicates absorption of vacancies from the precipitate whereas climb down is due to creation of vacancies in the precipitate.

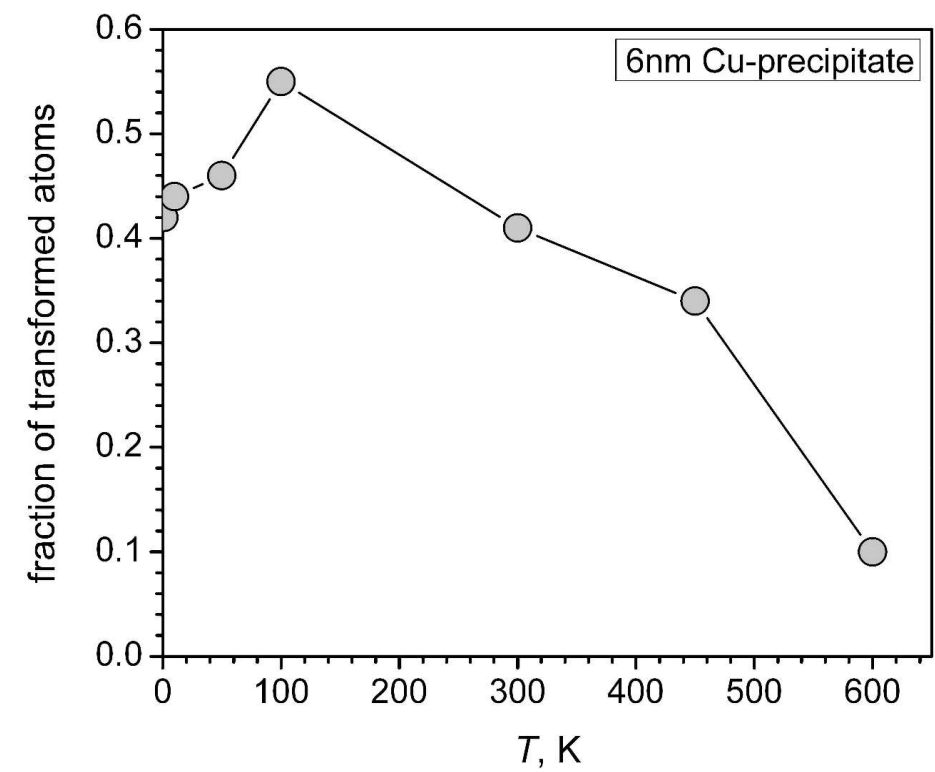

Fig. 9. Temperature-dependence of the fraction of the atoms transformed into FCC-like structure in $6 \mathrm{~nm}$ precipitate after dislocation breakaway. 


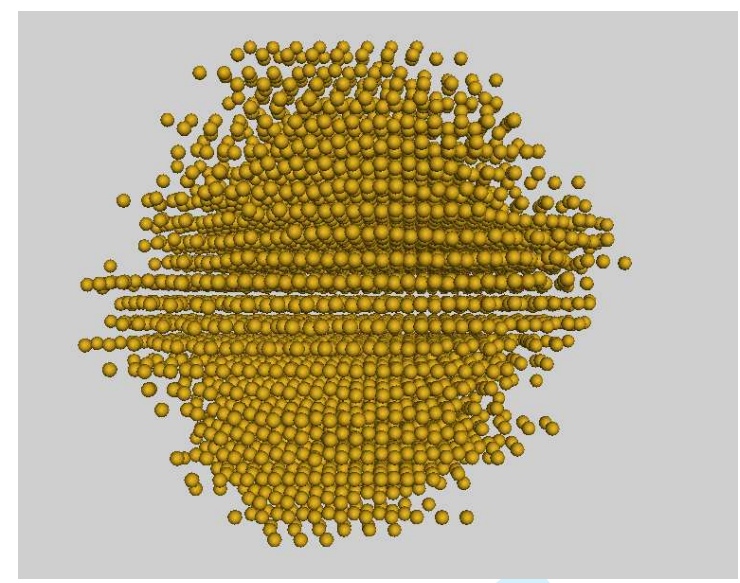

(a)

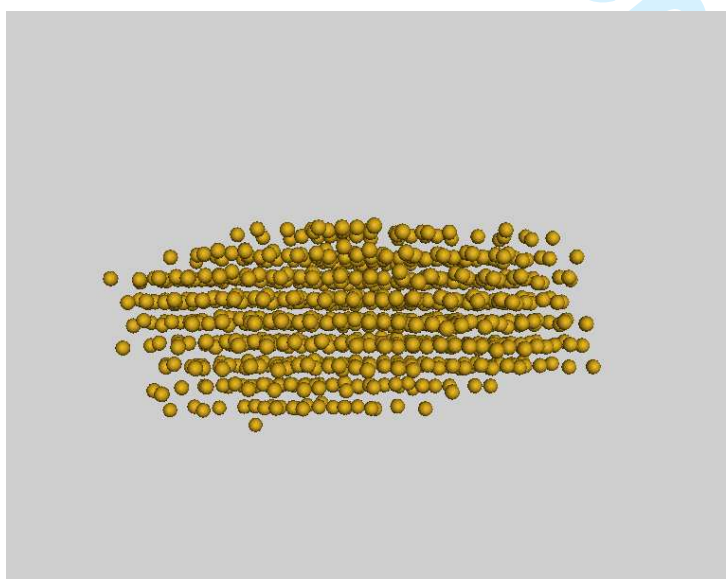

(c)

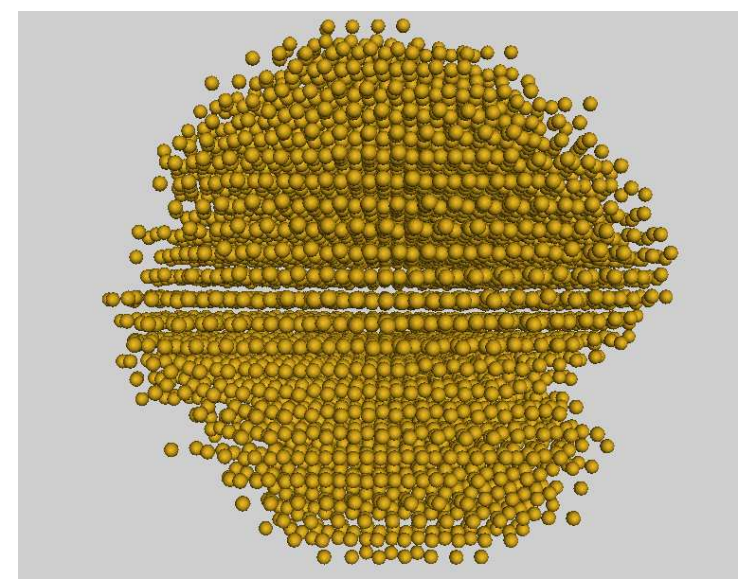

(b)

Fig. 10. Configuration of the atoms transformed into FCC-like structure inside a $6 \mathrm{~nm}$ precipitate after dislocation breakaway at (a) $10 \mathrm{~K}$, (b) $100 \mathrm{~K}$ (maximum transformed fraction) and (c) $600 \mathrm{~K}$. 


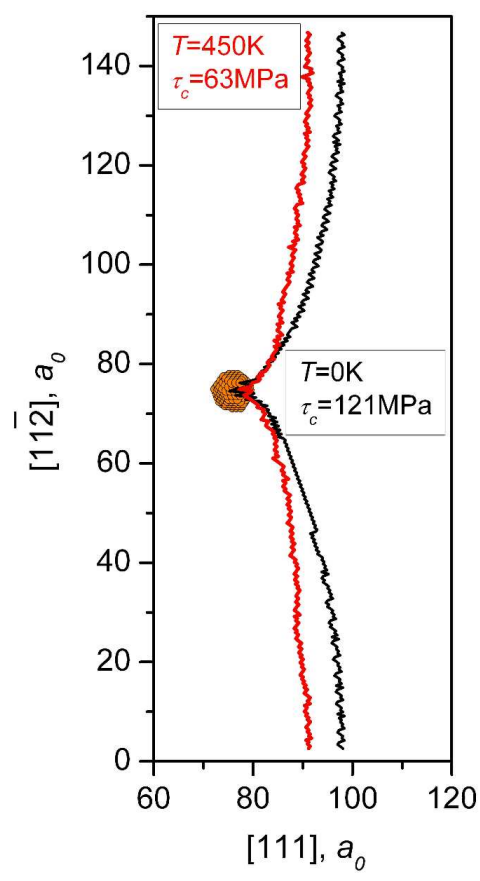

(a)

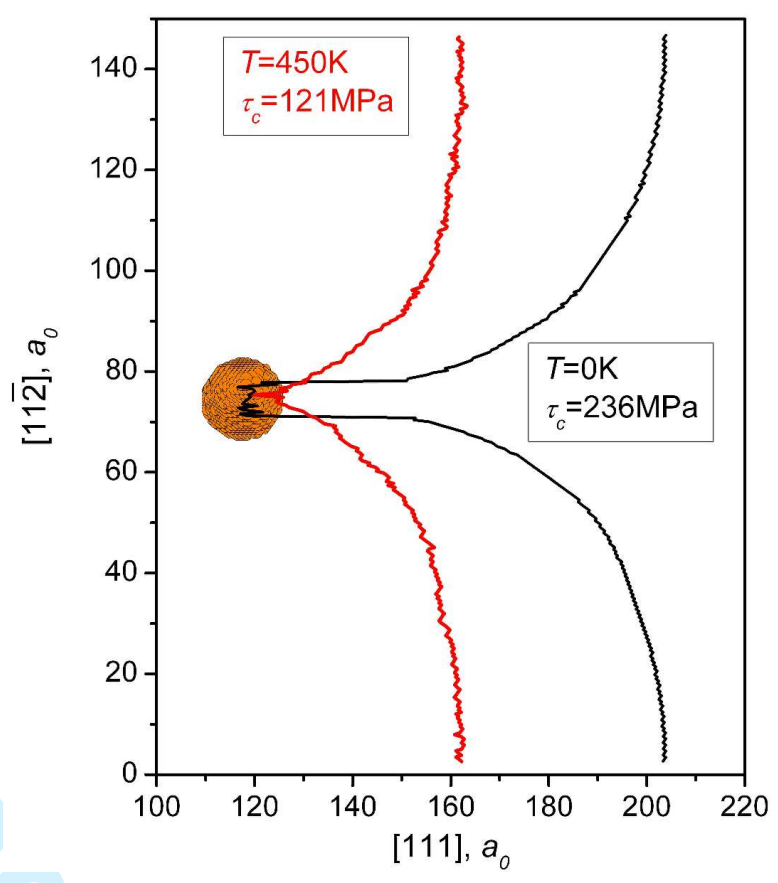

(b)

Fig. 11. Critical line shape in the (1 $\overline{1} 0)$ plane for a dislocation passing a row of (a) $2 \mathrm{~nm}$ and (b) $4 \mathrm{~nm}$ $\mathrm{Cu}$ precipitates with spacing $41.4 \mathrm{~nm}$ in $\mathrm{Fe}$ at the temperature indicated.

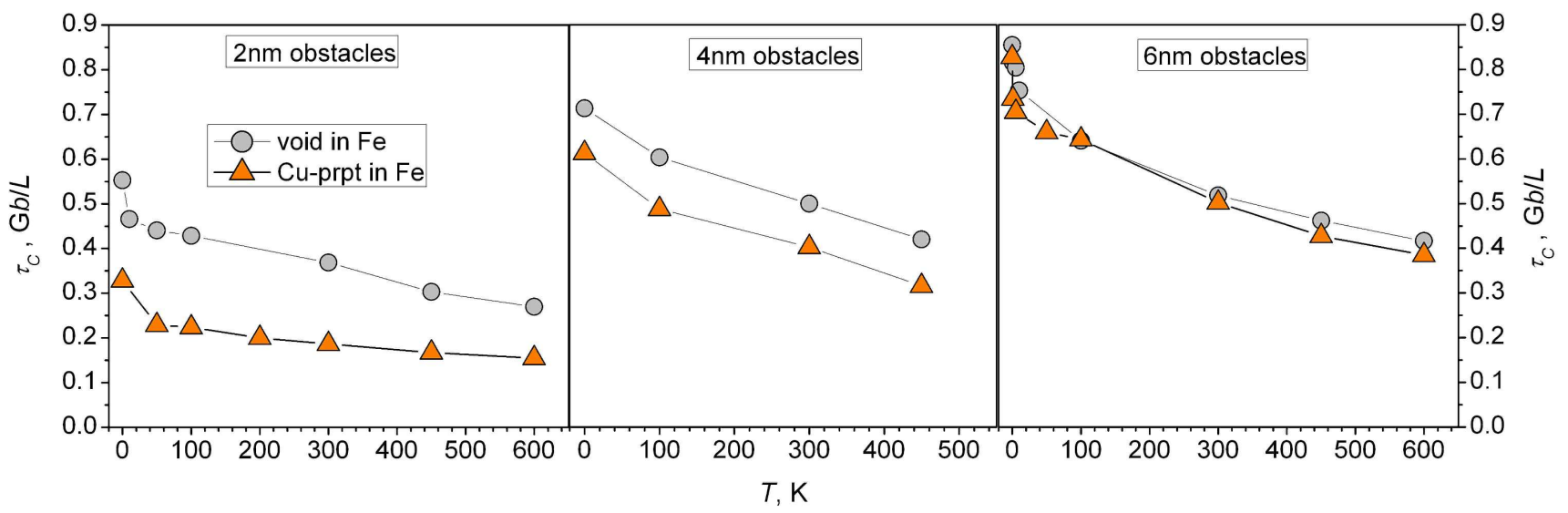

Fig. 12. Plots of $\tau_{\mathrm{c}}$ versus $T$ for $\mathrm{Cu}$ precipitates and voids in Fe for $D=2,4$ and $6 \mathrm{~nm}$, as indicated. $L=$ $41.4 \mathrm{~nm}$ and $\dot{\varepsilon}=5 \times 10^{6} \mathrm{~s}^{-1}$. 


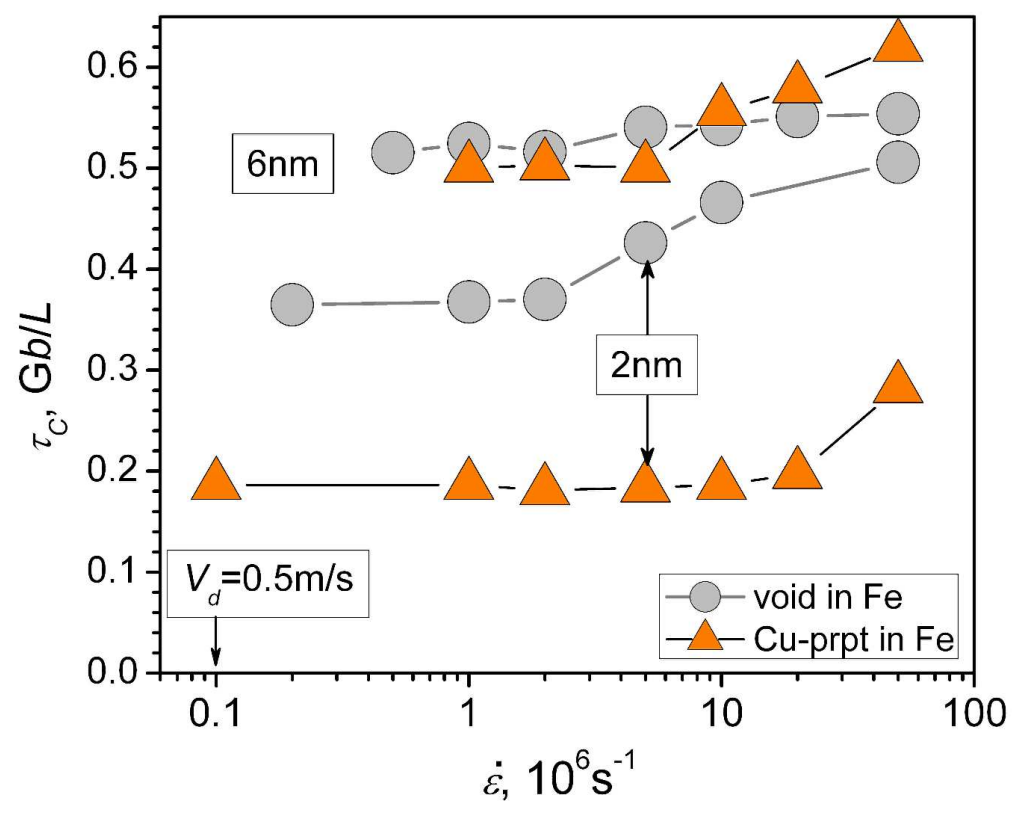

Fig. 13. Variation of $\tau_{\mathrm{c}}$ with applied strain rate for 2 and $6 \mathrm{~nm} \mathrm{Cu}$ precipitates (triangles) and voids (circles) in $\mathrm{Fe}$ at $300 \mathrm{~K}$. The dislocation velocity, $V_{\mathrm{d}}$, in steady state flight depends on the model size through the Orowan relation between $\dot{\varepsilon}, V_{\mathrm{d}}$ and dislocation density [45]. For the lowest value $\dot{\varepsilon}=10^{5} \mathrm{~s}^{-1}$ here, $V_{\mathrm{d}}=0.5 \mathrm{~ms}^{-1}$, as indicated. 